\title{
Influência da frequência de suplementação no consumo, na digestibilidade e na fermentação ruminal em novilhos de corte mantidos em pastagem de capim-marandu
}

\author{
Juciléia Aparecida da Silva Morais ${ }^{1,2}$, Telma Teresinha Berchielli, ${ }^{1,4}$, Maria Fernanda Soares \\ Queiroz ${ }^{1,2}$, Abdelhafid Keli ${ }^{3}$, Ricardo Andrade Reis ${ }^{1,4}$, Samuel Figueirêdo de Souza ${ }^{1}$ \\ ${ }^{1}$ Faculdade de Ciências Agrárias e Veterinárias - UNESP, Jaboticabal - SP. \\ 2 Bolsista da Fundação de Apoio à Pesquisa do Estado de São Paulo - FAPESP. \\ ${ }^{3}$ Unité de Recherche sur la Production Animale, INRA - Centre Régional de Tanger, Tanger, Marrocos. \\ ${ }^{4}$ Membro do INCT-CA.
}

RESUMO - Utilizaram-se nove novilhos Nelore fistulados no rúmen mantidos em nove piquetes de capim-marandu (Brachiaria brizantha cv. Marandu) sob suplementação diária (sete vezes por semana); de segunda a sexta-feira (cinco vezes por semana); ou às segundas, quartas e sextas-feiras (três vezes por semana). Amostras de líquido ruminal foram coletadas em dois dias: um dia em que todos os animais receberam suplemento (dia 1) e outro subsequente, no qual somente os animais sob suplementação diária receberam suplemento (dia 2). A frequência de suplementação não alterou a ingestão de matéria seca de forragem, a ingestão de matéria seca total e a digestibilidade total da matéria seca. As variáveis foram afetadas somente pelo período, com redução significativa do mês de março para o mês de maio. A frequência de suplementação não afetou o pH ruminal. Para $\mathrm{N}-\mathrm{NH}_{3}$ ruminal, observou-se interação frequência de suplementação $\times$ dia de coleta $\times$ horário de coleta. No dia 1 a concentração de $\mathrm{N}_{-} \mathrm{NH}_{3}$ não diferiu entre os horários após a suplementação entre os animais sob suplementação diária, enquanto no dia 2 houve um pico de produção de $\mathrm{N}-\mathrm{NH}_{3} 3$ horas após a suplementação. Entre os animais sob suplementação cinco vezes por semana, a diferença entre os dias 1 e 2 foi ocasionada pelo tempo 12 do dia 2 (7 mg/dL). $\mathrm{Na}$ suplementação três vezes por semana, no dia 1 o pico de $\mathrm{N}-\mathrm{NH}_{3}$ ocorreu 3 a 9 horas após a suplementação. A frequência de suplementação afetou somente a concentração de AGCC totais no dia 1 e a concentração de ácido butírico no dia 2 . O mês do ano não afeta o $\mathrm{pH}$ e a concentração de $\mathrm{N}_{-} \mathrm{NH}_{3}$, mas os AGCC diminuem significativamente do mês de março para o mês de maio.

Palavras-chave: ácidos graxos de cadeia curta, amônia ruminal, capim tropical, estratégia de suplementação, pH ruminal, transição águas/secas

\section{Influence of supplementation frequency on intake, digestibility and ruminal fermentation in beef cattle steers grazing palisade grass}

\begin{abstract}
Nine ruminally fistulated Nellore steers were located in nine paddocks of palisade grass (Brachiaria brizantha cv. Marandu) pasture under daily supplementation (seven times per week), from Monday to Friday (five times per week) or Monday, Wednesday and Friday (three times per week). Ruminal fluid was sampled on two consecutive days. On the first day, all the animals that were supplemented (D1) and other subsequent day in which only for the animals under daily supplementation received the supplement (D2). The supplementation frequency did not affect the forage DMI, total DMI and DMD. The DMI and DMD were influenced by the experimental period, with reduction from March to May. Ruminal $\mathrm{pH}$ was not affected by the supplementation frequency. Supplementation frequency $\times$ collection day $\times$ collection hour interaction was observed for ruminal $\mathrm{NH}_{3}-\mathrm{N}$. No difference in the D1 was observed in $\mathrm{NH}_{3}-\mathrm{N}$ concentration among the hours after supplementation in the daily supplementation frequency, while in the D2 there was a peak of $\mathrm{NH}_{3}-\mathrm{N}$ production 3 hours after supplementation. Among the animals under five times per week supplementation, the difference between D1 and D2 was due to the time 12 of the D2 $(7 \mathrm{mg} / \mathrm{dL})$. In the three times per week, the $\mathrm{NH}_{3}-\mathrm{N}$ concentration in D1 peaked at 3-9 hours after supplementation. The supplementation frequency only affected total SCFA concentration in the $\mathrm{D} 1$ and butyric acid concentration in the D2. The month of the year did not affect the ruminal $\mathrm{pH}$ and $\mathrm{NH}_{3}-\mathrm{N}$ concentration. However, the SCFA concentration was significantly reduced from March to May.
\end{abstract}

Key Words: rainy/dry transition, ruminal ammonia, ruminal $\mathrm{pH}$, short-chain fatty acids, supplementation strategy, tropical grass 


\section{Introdução}

A suplementação alimentar de bovinos criados em pastagens pode entrar no sistema de produção com o objetivo de corrigir deficiências de nutrientes e/ou potencializar o desempenho animal. Sendo o suplemento geralmente um insumo de alto custo, há necessidade de fornecê-lo de forma racional para não comprometer a eficiência econômica do sistema de produção. Por isso, a escolha de uma alternativa de suplementação adequada é importante, não só do ponto de vista produtivo, mas também do ponto de vista econômico, para proporcionar melhores respostas para os produtores. Considerando esse último objetivo, pesquisadores têm buscado alternativas para reduzir os custos de produção sem comprometer o nível de produção, a fim de disponibilizar no mercado um produto competitivo e de qualidade. Uma das maneiras de alcançar esse objetivo é diminuir os gastos com mãode-obra e a utilização de maquinários e equipamentos para a distribuição do suplemento por meio da redução da frequência de fornecimento do suplemento aos animais (Berchielli et al., 2006). Os resultados dessa estratégia de suplementação, em geral, têm sido satisfatórios, com pequeno ou nenhum efeito negativo sobre o desempenho dos animais (Berchielli et al., 2006) ou sobre a ingestão e a digestibilidade de nutrientes (Huston et al., 1999a,b; Bohnert et al., 2002a,b). No entanto, os fatores envolvidos na obtenção dessas respostas ainda não estão totalmente elucidados.

Estudos sobre a relação entre a alteração da frequência de fornecimento e a fermentação ruminal são escassos com animais mantidos em pastagens. Os trabalhos sobre os efeitos da redução da frequência de suplementação no metabolismo de ruminantes, em sua maioria, foram realizados com animais em confinamento (Bohnert et al., 2002ab; Farmer et al., 2004), onde o controle das condições experimentais pode diminuir as interações com a dieta consumida, ao contrário do manejo em pastagem.

Este trabalho foi desenvolvido com o objetivo de avaliar as consequências da redução da frequência de fornecimento de suplemento proteico-energético na ingestão de matéria seca (MS), na digestibilidade da matéria seca e na fermentação ruminal em novilhos mantidos em pastagem de capim-marandu durante o período de transição águas/seca.

\section{Material e Métodos}

$\mathrm{O}$ experimento foi realizado em área pertencente ao Departamento de Zootecnia da Faculdade de Ciências
Agrárias e Veterinárias, Universidade Estadual Paulista, situada no município de Jaboticabal, São Paulo, no período de março a maio de 2006.

Foram utilizados nove novilhos da raça Nelore, fistulados no rúmen, com peso corporal (PC) inicial de $298 \pm 50,1 \mathrm{~kg}$. Os animais foram distribuídos, juntamente com outros 45 novilhos de mesma raça e peso corporal similar, em nove piquetes de 2 hectares cada, formados com Brachiaria brizantha cv. Marandu. Cada piquete continha um bebedouro metálico e comedouros plásticos para fornecimento do suplemento. O suplemento foi formulado com glúten de milho para fornecer proteína de escape ruminal (Tabela 1), com o objetivo de aumentar o aporte de proteína intestinal; levedura seca de cana-deaçúcar para disponibilizar nitrogênio para as bactérias ruminais e para aumentar a palatabilidade do suplemento, tendo em vista a baixa aceitabilidade do glúten de milho pelos animais; e polpa cítrica como fonte de energia. Os animais receberam suplemento proteico-energético na quantidade de $3,5 \%$ do $\mathrm{PC} /$ semana.

O suplemento foi oferecido aos animais diariamente ( 7 vezes por semana); de segunda a sexta-feira ( 5 vezes por semana); ou às segundas, quartas e sextas-feiras ( 3 vezes por semana). Nos grupos com fornecimento 5 e 3 vezes por semana, em cada fornecimento, os animais receberam 0,7 e $1,17 \%$ do PC de suplemento, respectivamente, para que, ao final de 7 dias, recebessem quantidade igual a $0,5 \%$ do $\mathrm{PC} /$ dia. O suplemento foi fornecido ao grupo de animais de cada piquete às $9 \mathrm{~h}$ e em cochos plásticos. O suplemento era rapidamente consumido pelos animais em 15 minutos, em média. Os animais foram pesados a cada 28 dias para ajuste da oferta de suplemento de acordo com o peso corporal.

O sistema de pastejo usado foi o contínuo, com taxa de lotação variável. A determinação da massa de forragem disponível foi realizada a cada 28 dias, por meio do lançamento de um quadrado metálico de $1 \times 1 \mathrm{~m}$ em cinco diferentes pontos de cada piquete, escolhidos previamente para representar as características de estrutura e disponibilidade médias de cada piquete (Tabela 2). A forragem contida no quadrado foi cortada rente ao solo.

A composição botânica da forragem aparentemente consumida pelos animais foi estimada pela metodologia dos n-alcanos (Tabela 3), utilizando-se o perfil de alcanos dos componentes da dieta (folha verde, colmo verde e material morto), reduzindo as discrepâncias ao quadrado entre as concentrações fecais de cada um dos alcanos (expressas como proporção da concentração total de alcanos) corrigidas para sua recuperação fecal relativa e as proporções teóricas de cada alcano nas fezes (Dove \& Moore, 1995; Dove etal., 1999). 
Tabela 1 - Proporção e composição bromatológica dos ingredientes do suplemento, em \% da matéria seca

\begin{tabular}{|c|c|c|c|c|}
\hline & & & & \\
\hline & Glúten de milho-60 & Levedura seca & Polpa cítrica & Mistura mineral $^{1}$ \\
\hline$\%$ no suplemento & 56,5 & 23,5 & 14,0 & 6,0 \\
\hline Matéria seca & 91,76 & 90,13 & 89,03 & - \\
\hline Matéria orgânica & 98,49 & 93,27 & 93,60 & - \\
\hline Proteína bruta & 66,15 & 34,39 & 9,45 & - \\
\hline Extrato etéreo & 3,20 & 0,20 & 2,00 & - \\
\hline Fibra em detergente neutro & 10,94 & 2,53 & 22,47 & - \\
\hline Fibra em detergente ácido & 7,82 & 1,30 & 17,03 & - \\
\hline Carboidratos não-fibrosos ${ }^{2}$ & 18,19 & 56,14 & 59,67 & - \\
\hline Carboidrato totais ${ }^{2}$ & 29,14 & 58,67 & 82,15 & - \\
\hline Nutrientes digestíveis totais ${ }^{3}$ & 73,11 & 75,73 & 73,83 & - \\
\hline
\end{tabular}

${ }^{1}$ Níveis de garantia por $1.000 \mathrm{~g}$ do produto (cálcio: $155 \mathrm{~g}$; fósforo: $80 \mathrm{~g}$; magnésio: $10 \mathrm{~g}$; enxofre: $40 \mathrm{~g}$; sódio: $130 \mathrm{~g}$; cobre: $1.350 \mathrm{mg}$; manganês: $1.040 \mathrm{mg}$; zinco; $5.000 \mathrm{mg}$; iodo: $100 \mathrm{mg}$; cobalto: $80 \mathrm{mg}$; selênio: $26 \mathrm{mg}$; flúor (máx.): $800 \mathrm{mg}$ ).

${ }^{2}$ Carboidratos totais $(\mathrm{CT})=100-(\mathrm{PB}+\mathrm{EE}+$ Cinzas $)$; carboidratos não-fibrosos $=\mathrm{CT}-\mathrm{FDN}$

${ }^{3}$ Segundo Detmann et al. (2008).

Tabela 2 - Massa de forragem disponível, disponibilidade de matéria verde seca e de matéria seca de folha verde, oferta de forragem e relação folha verde:colmo verde do capim-marandu no período de fevereiro a maio de 2006 (média de nove observações)

\begin{tabular}{lccc}
\hline & & Período & \multirow{2}{*}{ Média } \\
\cline { 2 - 3 } & Março & Abril & Maio \\
\hline Massa de forragem disponível (t MS/ha) & 6,62 & 7,28 & 5,34 \\
Disponibilidade de matéria verde seca & 5,19 & 5,59 & 4,07 \\
Disponibilidade de matéria seca de folha verde (t MS/ha) & 1,69 & 1,41 & 4,95 \\
Oferta de forragem (kg de MS/100 kg PC) & 7,09 & 1,63 & 6,38 \\
Relação folha verde:colmo verde & 0,49 & 7,58 & 0,47 \\
\hline
\end{tabular}

De acordo com os cálculos realizados, nos dois períodos experimentais, os animais consumiram exclusivamente folha. Assim, a composição da forragem aparentemente consumida foi igual à concentração na fração folha verde do capim.

A ingestão e a digestibilidade da MS foram determinadas em dois períodos de 12 dias: de 15 a 27 de março e de 1 a 12 de maio. Em cada período, os animais receberam diariamente 2 péletes de papel-filtro picado em pedaços de aproximadamente $1 \times 1 \mathrm{~cm}$ impregnados com os alcanos $\mathrm{C}_{32}$ e $\mathrm{C}_{36}$, conforme descrito por Mayes et al. (1986). No primeiro período, cada pélete continha $289,91 \mathrm{mg}$ do alcano $\mathrm{C}_{32}$ (n-dotriacontano) e $299,50 \mathrm{mg}$ do alcano $\mathrm{C}_{36}$ (n-hexatriacontano) e, no segundo período, 132,25 mg de $\mathrm{C}_{32}$ e $138,99 \mathrm{mg}$ de $\mathrm{C}_{36}$.

Os animais foram contidos individualmente e, com o auxílio de uma mangueira plástica de $2,5 \mathrm{~cm}$ de diâmetro reforçada com fibras de aço, foram depositados os péletes, via esôfago, diretamente no rúmen. Os sete primeiros dias de cada período foram destinados à estabilização dos alcanos na digesta. Nos cinco dias seguintes, realizou-se a coleta de uma amostra de fezes, diretamente do reto dos animais, no momento do fornecimento dos péletes, a qual foi acondicionada em saco plástico e congelada. No fim de cada período, uma amostra composta por animal e período foi formada com base no peso seco das amostras.

Com o objetivo de diminuir o manejo e o estresse dos animais, no primeiro dia de fornecimento dos péletes, os animais foram presos $1 \mathrm{vez}$ ao dia (às $7 \mathrm{~h}$ ) e receberam 2 péletes de alcanos de uma única vez. No dia seguinte, os animais foram presos 2 vezes ao dia (às 7 e às 16 h) e receberam um pélete de cada vez, e assim sucessivamente até o final do período experimental. O mesmo manejo foi adotado para a coleta de fezes, de modo que, no total de 5 dias de coleta de fezes foram 3 dias com 2 coletas diárias e 2 dias com uma única coleta diária de fezes.

As amostras de forragem e fezes foram secas em estufa com circulação forçada de ar a $55^{\circ} \mathrm{C}$ por 72 horas, moídas a $1 \mathrm{~mm}$ em moinho tipo Willey para posteriores análises. As concentrações de alcanos na forragem e fezes foram determinadas conforme metodologia de Mayes et al. (1986), modificada por Oliván \& Osoro (1999). A quantificação dos alcanos foi realizada por cromatografia gasosa utilizando-se um padrão externo que incorporava todos os alcanos $\left(\mathrm{C}_{21}\right.$ ao $\mathrm{C}_{36}$ ) em concentrações similares às presentes nas amostras. Outros detalhes sobre a metodologia dos n-alcanos podem ser consultados em Morais (2008). 
Tabela 3 - Composição bromatológica e fracionamento da proteína bruta na planta inteira de capim-marandu e na forragem aparentemente consumida

\begin{tabular}{|c|c|c|c|c|c|c|c|c|}
\hline & \multirow[b]{2}{*}{$\% \mathrm{MS}$} & \multicolumn{3}{|c|}{$\%$ da matéria seca } & \multicolumn{4}{|c|}{$\%$ da proteína bruta } \\
\hline & & $\begin{array}{l}\text { Matéria } \\
\text { orgânica }\end{array}$ & $\begin{array}{l}\text { Proteína } \\
\text { bruta }\end{array}$ & $\begin{array}{l}\text { Fibra em } \\
\text { detergente neutro }\end{array}$ & $\mathrm{A}+\mathrm{B} 1$ & B2 & B3 & $\mathrm{C}$ \\
\hline \multicolumn{9}{|c|}{ Planta inteira } \\
\hline Março & 35,92 & 93,05 & 3,03 & 77,33 & 41,01 & 26,35 & 19,92 & 12,70 \\
\hline Abril & 39,62 & 93,29 & 3,16 & 79,25 & 42,79 & 26,66 & 17,39 & 13,55 \\
\hline Maio & 47,99 & 93,30 & 2,28 & 78,50 & 42,32 & 24,81 & 5,76 & 29,06 \\
\hline Média & 41,18 & 93,21 & 2,82 & 78,36 & 42,03 & 25,94 & 14,34 & 18,44 \\
\hline \multicolumn{9}{|c|}{ Forragem aparentemente consumida } \\
\hline Março & 37,29 & 92,23 & 5,89 & 70,46 & 52,88 & 26,56 & 10,55 & 9,91 \\
\hline Abril & 32,29 & 91,00 & 7,55 & 68,68 & 33,20 & 39,82 & 18,15 & 8,82 \\
\hline Maio & 38,10 & 91,34 & 6,55 & 68,54 & 35,14 & 34,05 & 22,71 & 8,10 \\
\hline Média & 35,89 & 91,52 & 7,66 & 69,23 & 40,41 & 33,48 & 17,14 & 8,94 \\
\hline
\end{tabular}

A ingestão de matéria seca de forragem foi calculada de acordo com Mayes et al. (1986):

$$
\mathrm{IMS}=\frac{\mathrm{D}_{32}}{\frac{\mathrm{F}_{32}}{\mathrm{~F}_{33}} * \mathrm{C}_{33}-\mathrm{C}_{32}}
$$

em que: IMS = ingestão de MS de forragem ( $\mathrm{kg} / \mathrm{dia})$; $\mathrm{D}_{32}=$ quantidade administrada diariamente $(\mathrm{mg})$ do alcano externo $\mathrm{C}_{32} ; \mathrm{F}_{32}=$ concentração fecal do alcano externo $(\mathrm{mg} / \mathrm{kg} \mathrm{MS}) ; \mathrm{F}_{33}=$ concentração fecal do alcano interno $(\mathrm{mg} / \mathrm{kg} \mathrm{MS}) ; \mathrm{C}_{32}=$ concentração do alcano externo na dieta selecionada ( $\mathrm{mg} / \mathrm{kg} \mathrm{MS}) ; \mathrm{C}_{33}=$ concentração do alcano externo na dieta selecionada ( $\mathrm{mg} / \mathrm{kg} \mathrm{MS})$.

A digestibilidade da matéria seca (DMS) foi estimada pela relação entre a concentração do alcano interno $\mathrm{C}_{35}$ na dieta e nas fezes.

As amostras de líquido ruminal foram coletadas em dois períodos experimentais (25 e 26/3/2006 e 14 e 15/5/2006) para reconstituir o comportamento do $\mathrm{pH}$, nitrogênio amoniacal $\left(\mathrm{N}-\mathrm{NH}_{3}\right.$ ) e ácidos graxos de cadeia curta (AGCC) em 24 horas após o fornecimento do suplemento, entre os animais sob suplementação diária, e 36 horas entre os demais. As coletas foram realizadas em dois dias consecutivos, de forma que, no primeiro dia de coleta (dia 1), todos os animais receberam suplemento e, no segundo dia (dia 2), somente os animais sob suplementação diária receberam suplemento. Os tempos de coleta foram 0 (antes da suplementação), 3, 6, 9 e 12 horas, após a suplementação aos animais.

O conteúdo ruminal foi coletado manualmente e filtrado em um saco de algodão em um béquer. Aproximadamente $50 \mathrm{~mL}$ de líquido ruminal filtrado foi utilizado para determinação imediata do $\mathrm{pH}$ ruminal utilizando-se potenciômetro digital. A seguir, duas alíquotas de $50 \mathrm{~mL}$ foram congeladas a $-20^{\circ} \mathrm{C}$ em frasco plástico para posteriores análises de $\mathrm{N}-\mathrm{NH}_{3}$ e AGCC (Leventini et al., 1990). Após o descongelamento das amostras, a concentração de $\mathrm{N}-\mathrm{NH}_{3}$ no líquido ruminal foi determinada pelo sistema microKjeldahl, sem digestão ácida da amostra ( $2 \mathrm{~mL}$ de líquido ruminal $+13 \mathrm{~mL}$ de água destilada) e utilizando-se como base para destilação o hidróxido de potássio $2 \mathrm{~N}(5 \mathrm{~mL})$.

Os dados de ingestão de forragem, de suplemento, ingestão total e digestibilidade da matéria seca foram avaliados em delineamento em parcelas subdivididas, considerando nas parcelas o efeito da freqüência de suplementação e nas subparcelas o período experimental (mês do ano). Os dados foram submetidos à análise de variância pelo procedimento PROC GLM pelo pacote estatístico SAS (2003) e as médias comparadas pelo teste Tukey a 5\% de significância.

As análises das variáveis $\mathrm{pH}, \mathrm{N}-\mathrm{NH}_{3}$ e AGCC no líquido ruminal foram realizadas mediante subdivisão de parcelas, de acordo com os tempos de avaliação (split-plot no tempo) (Steel et al., 1997). Para as análises dos dados

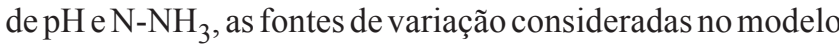
foram a frequência de suplementação, o período experimental (março e maio), o dia de coleta (dia 1 e dia 2), o horário de coleta ( 0 a 12 horas após a suplementação) e as possíveis interações. Os dados de concentração de AGCC foram analisados por dia de coleta (dia 1 e dia 2) separadamente, considerando no modelo os fatores frequência de suplementação, período experimental, horário de coleta e as possíveis interações. O procedimento MIXED (SAS, 2003) foi usado para analisar as variáveis de fermentação ruminal, considerando o animal dentro da interação frequência de suplementação $\times$ período como efeito aleatório. 


\section{Resultados e Discussão}

Não houve interação significativa $(\mathrm{P}>0,05)$ entre frequência de suplementação e mês do ano para nenhuma das variáveis relacionadas à ingestão e digestibilidade de matéria seca (Tabela 4). A redução na frequência de suplementação não alterou a ingestão ( $\mathrm{kg} / \mathrm{dia}$ e \% do PC) de forragem, de suplemento ou de MS total (forragem + suplemento) nem a digestibilidade da MS ( $\mathrm{P}>0,05)$, no entanto, essas variáveis foram influenciadas $(\mathrm{P}<0,05)$ pelo mês do ano.

Os resultados encontrados neste trabalho confirmam relatos de outros autores de que a frequência de suplementação não afeta a ingestão de matéria seca (Coleman \& Wyatt, 1982; Huston et al., 1999a). Por outro lado, outras pesquisas indicam redução na ingestão de forragem com a diminuição na frequência de suplementação (Beaty et al., 1994; Huston et al., 1999b; Bohnert et al., 2002c). Huston et al. (1999b) comprovaram decréscimo de 38 e $27 \%$ na ingestão de forragem em vacas sob suplementação 3 dias e 1 dia/ semana, respectivamente, em comparação à suplementação diária. Da mesma forma, Bohnert et al. (2002c) relataram decréscimo linear na ingestão de feno por cordeiros quando a suplementação foi realizada diariamente, a cada 3 dias ou a cada 6 dias. Em novilhos, Bohnert et al. (2002a) observaram efeito quadrático da frequência de suplementação sobre a ingestão de forragem, que foi maior nos animais que receberam suplemento 3 vezes/semana. Huston et al. (1999b), Farmer et al. (2001) e Bohnert et al. (2002c) sugeriram que a redução na ingestão de forragem pode ser decorrente do efeito substitutivo da forragem pelo suplemento nos animais sob suplementação irregular e que esse efeito é mais pronunciado no dia da suplementação, em decorrência da maior quantidade de suplemento ingerida a cada evento de suplementação (Farmer et al., 2001).

No entanto, essas pesquisas foram realizadas com animais em confinamento ou em estudos de metabolismo.
Até o momento, um dos poucos trabalhos com os animais em pastagem foi feito por Schauer et al. (2005), que estimaram ingestão de matéria seca de vacas mantidas em pastagem nativa nos Estados Unidos e verificaram que a ingestão de MS de forragem foi similar entre os animais sob suplementação diária ou a cada 6 dias.

Neste trabalho, observou-se diminuição de $32 \%$ na ingestão de matéria seca de forragem do mês de março para o mês de maio $(\mathrm{P}<0,05)$, enquanto a ingestão de MS total decresceu 25,8\% no mesmo período. A ingestão de MS de suplemento aumentou de acordo com o peso dos animais. A ingestão de MS de forragem por animais em pastejo está relacionada diretamente à disponibilidade, estrutura e qualidade da forragem. Em condições tropicais, a massa, a oferta de forragem e a estrutura do dossel são as características da forragem que mais influenciam a ingestão pelos animais em pastejo (Reis \& da Silva, 2006). Neste trabalho, a redução de $32 \%$ na ingestão MS de forragem do mês de março para o mês de maio (Tabela 4) esteve associada à redução de 22, 17 e 24\% na disponibilidade de matéria verde seca (MVS), de MS de lâminas foliares verdes e na oferta de forragem, respectivamente, nesse mesmo período (Tabela 2).

Os efeitos da redução da frequência de suplementação na digestibilidade têm sido variáveis. Coleman \& Wyatt (1982), Hunt et al. (1989) e Bohnert et al. (2002a) observaram redução na digestibilidade da MS com a diminuição na frequência de suplementação, enquanto Beaty et al. (1994) constataram aumento na digestibilidade da MS quando novilhos receberam suplemento 1 ou 3 vezes por semana. Bohnert et al. (2002a) observaram que a digestibilidade da MO e FDN não foram afetadas em novilhos alimentados com feno de baixa qualidade (5\% de PB) recebendo suplemento 1,3 ou 6 vezes por semana. De acordo com Farmer et al. (2001), a redução na digestibilidade da MO decorreu de alterações na fermentação ruminal.

Tabela 4 - Ingestão de matéria seca de forragem, de suplemento e total (forragem + suplemento) e digestibilidade da matéria seca em novilhos mantidos em pastagem de capim-marandu sob suplementação em diversas frequencias

\begin{tabular}{|c|c|c|c|c|c|c|c|}
\hline & \multicolumn{3}{|c|}{ Frequência de suplementação ${ }^{1}$} & \multirow[t]{2}{*}{$\mathrm{EPM}^{1}$} & \multicolumn{2}{|c|}{ Mês do ano } & \multirow[t]{2}{*}{$\mathrm{EPM}$} \\
\hline & Diária & $\begin{array}{l}5 \text { vezes por } \\
\text { semana }\end{array}$ & $\begin{array}{c}3 \text { vezes por } \\
\text { semana }\end{array}$ & & Março & Maio & \\
\hline Ingestão de MS da forragem, \%PC & 1,72 & 1,97 & 1,95 & 0,126 & $2,30 \mathrm{~A}$ & $1,46 \mathrm{~B}$ & 0,140 \\
\hline Ingestão de MS do suplemento, $\mathrm{kg} / \mathrm{dia}$ & 1,71 & 1,58 & 1,30 & 0,131 & $1,49 \mathrm{~B}$ & $1,54 \mathrm{~A}$ & 1,516 \\
\hline Ingestão de MS total, $\mathrm{kg} / \mathrm{dia}$ & 7,53 & 7,79 & 7,53 & 0,420 & $8,73 \mathrm{~A}$ & $6,48 \mathrm{~B}$ & 0,581 \\
\hline
\end{tabular}

${ }^{1}$ Erro-padrão da média.

AB Médias seguidas por letras diferentes nas linhas diferem $(\mathrm{P}<0,05)$ pelo teste Tukey. 
No presente trabalho, a digestibilidade da MS também foi afetada pelo mês do ano, o que pode ser consequência da redução na disponibilidade de forragem, principalmente de folhas, que diminui a possibilidade de seleção de material de melhor qualidade pelos animais.

$\mathrm{O}$ pH ruminal não foi alterado $(\mathrm{P}>0,05)$ pela frequência de suplementação, pelo mês do ano (período experimental) ou pelo dia de coleta (Figura 1). No entanto, houve efeito de horário de coleta $(\mathrm{P}<0,001)$ e interação dia $\times$ horário de coleta $(\mathrm{P}<0,01)$. No dia 1 , observou-se decréscimo do $\mathrm{pH}$ ruminal ao longo do dia, de modo que o horário 0 (antes da suplementação) foi significativamente superior aos demais. $\mathrm{O}$ pH decresceu até 6-9 horas após a suplementação e voltou a subir após a 9a hora. No entanto, 12 horas após a suplementação, foi significativamente inferior ao tempo 0 do dia 1 e, inclusive ao tempo 0 do dia 2 . No dia 2 , o pH ruminal não variou ao longo do dia $(\mathrm{P}>0,05)$. Apesar das diferenças observadas, a média de $\mathrm{pH}$ ruminal foi de 6,84 (6,80 no dia 1 e 6,88 no dia 2), com valor mínimo de 6,5 às 9 horas do dia 1. Os resultados diferem dos encontrados em outros trabalhos sobre o efeito da redução da frequência de suplementação no pH ruminal. Beaty et al. (1994), Farmer et al. (2001) e Bohnert et al. (2002b) relataram que o $\mathrm{pH}$ ruminal foi menor no dia em que todos os animais receberam suplemento (dia 1) em comparação ao dia em que somente o grupo sob suplementação diária recebia suplemento (dia 2).

Os valores observados neste trabalho estão acima do indicado por Mould et al. (1983) para evitar decréscimo na digestão da fibra $(>6,2)$. Valores de $\mathrm{pH}$ superiores a 6,5 , mesmo nos grupos que recebiam maiores quantidades de suplemento a cada evento de suplementação $(0,7$ ou $1,17 \%$ do PC nos animais sob suplementação 5 e 3 vezes por semana, respectivamente) podem ser explicados pelas características do suplemento. Além de o suplemento ser constituído principalmente por alimentos proteicos (glúten de milho e levedura), a fonte de energia era constituída por polpa cítrica, rica em pectina. A degradação de alimentos ricos em pectina, em comparação a alimentos ricos em amido, como o milho, aumenta a relação acético:propiônico
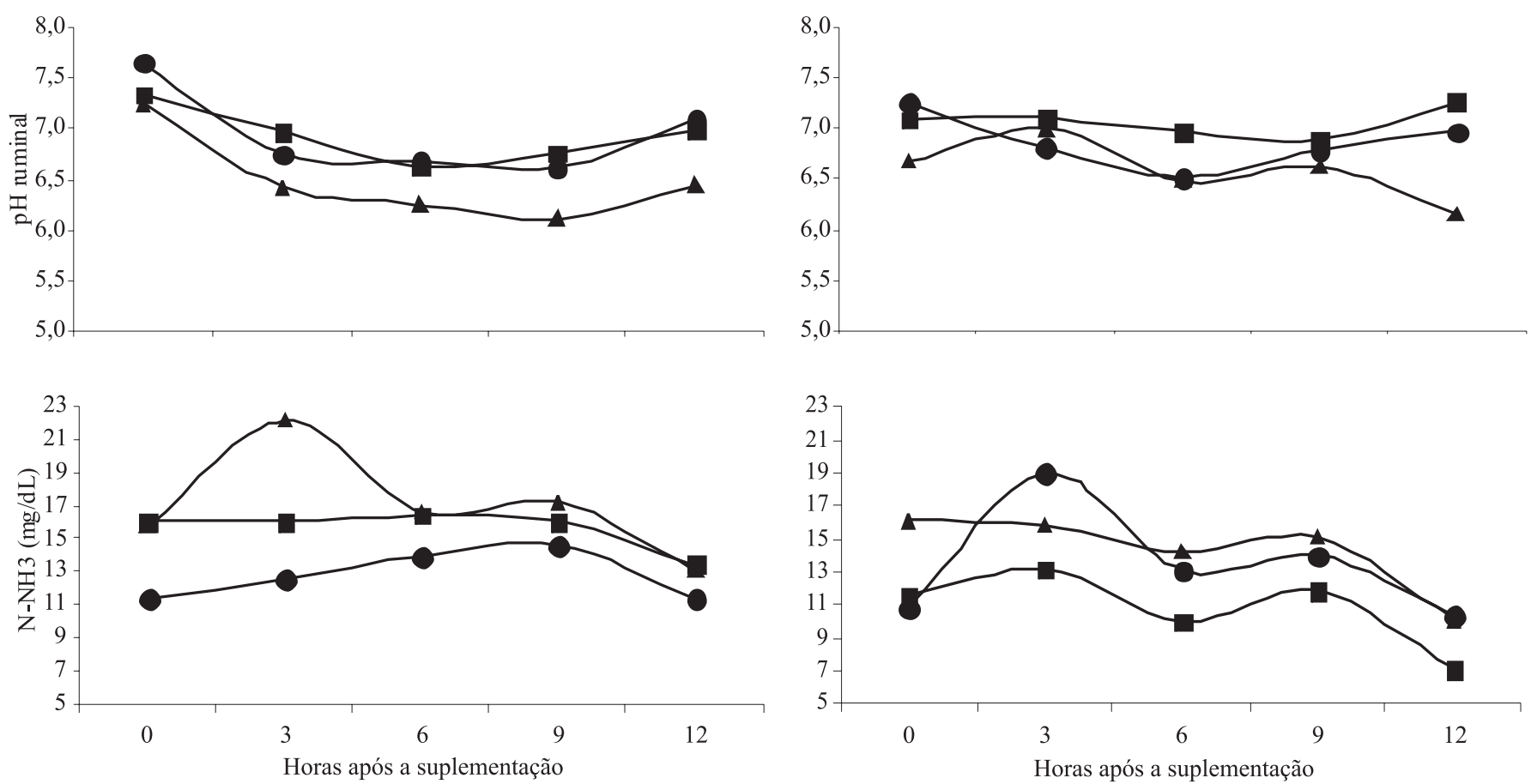

Dia 1 = dia em que todos os grupos receberam suplemento; Dia $2=$ dia em que somente o grupo TOD recebeu suplemento; $\mathrm{N}^{\mathrm{N}} \mathrm{NH}_{3}($ frequência de suplementação $\times$ dia $\times$ horário de coleta, $\mathrm{P}<0,01)$.

Figura 1 - pH e concentração de $\mathrm{N}-\mathrm{NH}_{3}(\mathrm{mg} / \mathrm{dL}$ de líquido ruminal) no rúmen de novilhos mantidos em pastagem de capim-marandu sob suplementação diária $(\bullet), 5$ vezes por semana ou 3 vezes por semana $(\mathbf{A})$. 
e diminui a produção de ácido lático, o que reflete em menor decréscimo do $\mathrm{pH}$ ruminal em animais mantidos com dietas contendo polpa cítrica (Carey et al., 1993).

A concentração de $\mathrm{N}-\mathrm{NH}_{3}$ no rúmen foi afetada pelo dia ( $P<0,001)$ e pelo tempo de coleta $(\mathrm{P}<0,001)$, com interação significativa entre frequência de suplementação e dia de coleta $(\mathrm{P}<0,001)$ e frequência de suplementação $\times$ dia de coleta $\times$ horário de coleta $(\mathrm{P}<0,01)$ (Figura 1). Quando os animais receberam suplementação diária, observou-se pico de produção de $\mathrm{N}-\mathrm{NH}_{3}$ após 3 horas a suplementação, superior aos tempos 0 e 12 . No grupo com suplementação 5 vezes por semana, houve diferença entre o dia 1 (dia em que foram suplementados) e o dia 2 (dia em que não receberam suplemento). No entanto, a diferença ocorreu no tempo 12 do dia 2, no qual a concentração de $\mathrm{N}-\mathrm{NH}_{3}$ foi muito baixa, próxima de $7 \mathrm{mg} / \mathrm{dL}$ de líquido ruminal, diferindo de todos os outros tempos de coleta. No grupo sob suplementação 3 vezes por semana, a concentração de $\mathrm{N}-\mathrm{NH}_{3}$ às 3,6 e 9 horas após suplementação (dia 1) foi superior à observada nos horários de 0 e 12 horas. O pico de $\mathrm{N}_{-} \mathrm{NH}_{3}$, atingido 3 horas após a suplementação nessa frequência de alimentação $(22,14 \mathrm{mg} / \mathrm{dL}$ de líquido ruminal) foi superior à concentração de $\mathrm{N}-\mathrm{NH}_{3}$ no rúmen dos animais sob suplementação diária e à daqueles sob suplementação 5 vezes por semana (a partir de 6 horas do dia 1 e durante todo o dia 2). De acordo com Owens \& Zinn (1988), a concentração de $\mathrm{N}^{-\mathrm{NH}_{3}}$ varia nos horários após a alimentação e sua intensidade depende do tipo de alimento. Com ureia, as concentrações máximas de $\mathrm{N}-\mathrm{NH}_{3}$ ocorrem entre 1 e 2 horas após seu fornecimento, enquanto em rações ricas em proteína vegetal, como as deste estudo, o pico ocorre 3 a 4 horas após o consumo de suplemento.

Considerando a interação frequência de suplementação $\times$ dia de coleta, no dia 1 a concentração de $\mathrm{N}-\mathrm{NH}_{3}$ no rúmen foi menor nos animais sob suplementação diária $(12,78 \mathrm{mg} / \mathrm{dL})(\mathrm{P}<0,05)$ e não diferiu $(\mathrm{P}>0,05)$ entre aqueles sob suplementação cinco $(15,68 \mathrm{mg} / \mathrm{dL})$ e três $(16,96 \mathrm{mg} / \mathrm{dL})$ vezes por semana. Essa maior concentração de $\mathrm{N}-\mathrm{NH}_{3}$ nos animais sob suplementação 3 e 5 vezes por semana no dia 1 pode ser explicada pela maior ingestão de suplemento nesses dois grupos. Para oferta semanal de suplemento de $3,5 \%$ do PC, os animais sob suplementação 3 a 5 vezes por semana e suplementação diária recebiam a cada fornecimento 1,$17 ; 0,7$ e $0,5 \%$ do PC, respectivamente. No dia 2 , a concentração de $\mathrm{N}_{-} \mathrm{NH}_{3}$ nos animais sob suplementação diária foi similar à daqueles que receberam suplemento 3 vezes por semana, cuja média foi 13,45 e $14,28 \mathrm{mg} / \mathrm{dL}$, respectivamente, e superior à observada nos animais sob suplementação 5 vezes por semana $(10,74 \mathrm{mg} / \mathrm{dL})$. A concentração de $\mathrm{N}^{-\mathrm{NH}_{3}}$ no grupo sob suplementação diária não variou entre os dias 1 e 2, enquanto, nos grupos que receberam suplemento 3 e 5 vezes por semana, a concentração média no dia 1 foi significativamente superior à do dia 2, como resultado da não-suplementação no dia 2 .

A similar concentração de $\mathrm{N}-\mathrm{NH}_{3}$ ruminal entre os animais sob suplementação 3 vezes por semana e diariamente no dia 2 , sugere um efeito prolongado da suplementação na fermentação ruminal mesmo com a infrequência na suplementação. Beaty et al. (1994) também notaram que bovinos alimentados com suplementos proteicos em intervalos não frequentes mantiveram elevados níveis de $\mathrm{N}-\mathrm{NH}_{3}$ ruminal, mesmo nos dias em que não receberam suplementação. De acordo com Farmer et al. (2004), a habilidade de sustentar a digestão, mesmo quando a proteína suplementar é fornecida com frequênica irregular comprova que ruminantes possuem mecanismos que diminuem os efeitos das variações no consumo de nutrientes. Segundo vários autores (Coleman \& Wyatt, 1982; Beaty et al., 1994; Bohnert et al., 2002ab; Farmer et al., 2004), esses mecanismos estão relacionados, principalmente, ao aumento na reciclagem de nitrogênio e na eficiência de utilização do nitrogênio reciclado. A maior eficiência de uso do nitrogênio ingerido é consequência de uma provável alteração na permeabilidade do trato gastrintestinal e/ou à regulação da excreção renal de ureia. Schauer et al. (2006) observaram que ovinos consumindo forrageira de baixa qualidade e recebendo suplementação a cada dez dias foram capazes de usar eficientemente o nitrogênio da dieta, similarmente aos animais sob suplementação diária.

A adaptação do organismo dos animais à inconstância no suprimento de nutrientes pode ser confirmada pelas concentrações de $\mathrm{N}-\mathrm{NH}_{3}$ nos animais sob suplementação 5 e 3 vezes por semana nos dois dias de coleta, quando houve suplementação, e no dia seguinte, quando não houve suplementação. Nos animais sob suplementação 3 vezes por semana, a redução da concentração de $\mathrm{N}-\mathrm{NH}_{3}$ do dia 1 para o dia 2 foi de $16 \%$, enquanto a redução da concentração nos animais sob suplementação 5 vezes por semana foi de $31 \%$. Esse fato indica que os animais sob suplementação 3 vezes por semana tiveram maior capacidade de manter os níveis de $\mathrm{N}-\mathrm{NH}_{3}$ em relação àqueles que receberam suplemento 5 vezes por semana. Também se destacou a concentração de $\mathrm{N}-\mathrm{NH}_{3}$ no rúmen no tempo 0 do dia 1 (anterior à suplementação) dos animais que receberam suplemento 3 vezes por semana. Esses animais estavam há quase 48 horas sem suplementação e, mesmo assim, a concentração de amônia não diferiu da observada nos animais que receberam suplemento há 24 horas (diariamente e 5 vezes por semana), o que confirma a capacidade desses animais em manter os níveis de amônia entre os eventos de suplementação. 
A manutenção das concentrações de $\mathrm{N}-\mathrm{NH}_{3}$ no rúmen favorece o crescimento das bactérias fibrolíticas, ajudando a manter a digestão da fibra, uma vez que essas bactérias têm preferência por $\mathrm{N}-\mathrm{NH}_{3}$ como fonte de nitrogênio (Russel et al., 1992). Esse evento contribui para reduzir os efeitos da diminuição da frequência de suplementação e explica a falta de efeito da ingestão irregular de nutrientes na ingestão de forragem, na digestibilidade (Tabela 4) e no desempenho de animais consumindo forragem de baixa qualidade (Farmer et al., 2004).

Concentração mínima de $5 \mathrm{mg}$ de $\mathrm{N}-\mathrm{NH}_{3} / \mathrm{dL}$ de líquido ruminal é necessária para manutenção da fermentação ruminal (Satter \& Slyter, 1974). Por outro lado, de acordo com Leng (1990), em condições tropicais, o nível de $\mathrm{N}-\mathrm{NH}_{3}$ deve ser superior a $10 \mathrm{mg} / \mathrm{dL}$ para melhora da digestão ruminal da matéria seca e superior a $20 \mathrm{mg} / \mathrm{dL}$ para aumento da ingestão de matéria seca. Os valores observados neste estudo estão dentro dessa faixa considerada adequada para a fermentação ruminal, mesmo nos animais sob suplementação em menor frequência. No entanto, a concentração de $\mathrm{N}^{-\mathrm{NH}_{3}} 36$ horas após a suplementação (sábado) nos animais sob suplementação 5 vezes por semana foi de $7 \mathrm{mg} / \mathrm{dL}$ e, considerando que o próximo fornecimento somente ocorreria após 35 horas (na segunda-feira), é provável que, em alguns períodos entre suplementação, os níveis de $\mathrm{N}-\mathrm{NH}_{3}$ nesses animais tenha sido inferior a $5 \mathrm{mg} / \mathrm{dL}$ de líquido ruminal, concentração mínima para a manutenção da fermentação ruminal (Satter \& Slyter, 1974).

Além das concentrações adequadas de $\mathrm{N}^{-\mathrm{NH}_{3}}$ no rúmen, atenuado pico de $\mathrm{N}-\mathrm{NH}_{3}$ contribui para conservação do nitrogênio ingerido e manutenção da atividade fibrolítica (Yang \& Russel, 1993). Nesse sentido, os animais que receberam suplementação diária e 5 vezes por semana tiveram pico de produção de $\mathrm{N}-\mathrm{NH}_{3}$ mais moderado em comparação aos do grupo sob suplementação 3 vezes por semana. Por outro lado, esses animais que receberam suplemento 3 vezes por semana mantiveram concentrações mais elevadas de $\mathrm{N}-\mathrm{NH}_{3}$ no rúmen no dia 2 em relação àqueles sob suplementação 5 vezes por semana. Esses resultados podem explicar a semelhança na digestibilidade da matéria seca (Tabela 4), que, associada à semelhante ingestão de matéria seca (Tabela 4), não afetou o desempenho (dados não apresentados) dos animais sob suplementação 3 e 5 vezes por semana em comparação aos suplementados diariamente (Morais, 2008).

Apesar dos baixos níveis de proteína na forragem ao longo dos períodos (Tabela 3), os animais mantiveram os níveis de $\mathrm{N}-\mathrm{NH}_{3}$ ruminal nos dois períodos experimentais, e em níveis adequados para manter a degradação da fibra $(13,54$ e $14,44 \mathrm{mg} / \mathrm{dL}$ no meses de março e maio, respectiva- mente). De acordo com Hunter \& Siebert (1985), animais zebuínos mantêm níveis de $\mathrm{N}-\mathrm{NH}_{3}$ mais elevados no fluido ruminal, se comparados a animais de origem europeia, quando alimentados com forragens de baixa qualidade.

As concentrações de ácidos graxos de cadeia curta (AGCC) (Tabela 5) não foram afetadas pelo dia de coleta $(\mathrm{P}>0,05)$, mas foram influenciadas pela frequência de suplementação e pelo mês do ano (período experimental). A interação frequência de suplementação $\times$ mês do ano foi significativa somente para a concentração de ácido acético no dia 2. A interação frequência de suplementação $x$ período experimental $\times$ horário de coleta não foi significativa $(\mathrm{P}>0,05)$ (Figura 2).

A frequência de suplementação somente afetou a concentração total de AGCC no dia 1 e a concentração de ácido butírico no dia 2 . No dia 1 , houve tendência $(\mathrm{P}=0,052)$ de efeito da frequência de suplementação sobre a concentração de ácido acético. No dia 1, a concentração de AGCC totais foi significativamente menor nos animais sob suplementação 3 vezes por semana em comparação àqueles que receberam suplemento 5 vezes por semana, os quais não diferiram daqueles sob suplementação diária. Apesar de, na suplementação 3 vezes por semana, os animais terem recebido maior quantidade de suplemento $(1,17 \%$ PC), o que favoreceria maior produção de AGCC (em virtude da maior quantidade de substrato fermentável), isso não foi observado. Além da tendência de menor concentração de ácido acético $(\mathrm{P}=0,052)$, a menor concentração de AGCC nos animais sob suplementação 3 vezes por semana pode estar relacionada à uma menor taxa inicial de fermentação da matéria orgânica após a suplementação, como consequência da não-suplementação no dia anterior. Por isso, os microrganismos ruminais demoraram 9 horas (Figura 2) para apresentar a produção de AGCC observadas nas outras frequências de suplementação. Por outro lado, apesar de os animais sob suplementação 3 e 5 vezes por semana não terem recebido suplemento no dia 2, a concentração de AGCC totais no rúmen foi similar à daqueles sob suplementação diária, o que evidencia um efeito prolongado da suplementação proteica na produção de AGCC.

Bohnert et al. (2002b) observaram, no dia em que todos os animais recebiam suplementação, efeito quadrático da frequência de suplementação com proteína by pass na concentração de AGCC totais, com maior concentração nos animais sob suplementação a cada três dias em comparação aos suplementados diariamente ou a cada seis dias. Esses autores também observaram que a suplementação de proteína by pass reduziu as mudanças nas proporções molares de acetato e propionato com a redução na frequência 
de suplementação em comparação à suplementação com proteína degradável no rúmen.

A relação acético:propiônico não foi afetada $(\mathrm{P}>0,05)$ pela frequência de suplementação, pelo período ou pela interação frequência de suplementação $\times$ período. A manutenção nas proporções dos dois ácidos pode ser explicada pela característica do suplemento, o qual não possuía nenhum ingrediente rico em amido, o que favoreceria a maior produção de ácido propiônico nas horas que sucedem à suplementação.

A relação acético:propiônico pode servir como indicativo da eficiência de utilização ruminal da energia. Durante a fermentação dos carboidratos, a produção de ácido acético libera, para o ambiente ruminal, mais moléculas de hidrogênio que na produção de ácido propiônico. O hidrogênio liberado precisa ser removido do rúmen para não inibir os sistemas enzimáticos (Miller, 1995). Uma das formas de eliminação desse hidrogênio é na forma de metano, que pode representar até $12 \%$ da perda de energia bruta ingerida por um ruminante (Johnson \& Johnson, 1995). A mesma relação acético:propiônico pode indicar semelhante produção de metano e similar eficiência de utilização da energia do alimento ingerido. Como neste trabalho não houve efeito da frequência de suplementação e do período experimental na relação acético:propiônico, pode-se supor que os animais foram igualmente eficientes na utilização ruminal da energia ingerida. A semelhança na ingestão de MS, na digestibilidade da MS, nos níveis de amônia ruminal e na relação acético:propiônico podem ajudar a explicar a falta de efeito da redução da freqüência de suplementação no desempenho animal (Morais, 2008).
No dia em que somente o grupo sob suplementação diária recebia suplemento (dia 2), a concentração de AGCC, tanto a total como a individual, foi afetada $(\mathrm{P}<0,05)$ pelo período experimental, e diminuiu do primeiro (março) para o segundo período (maio). Observou-se interação entre período e frequência de suplementação $(\mathrm{P}<0,05)$ para a concentração de ácido acético. A concentração de ácido acético nos animais sob suplementação diária não foi afetada $(\mathrm{P}>0,05)$ pelo período experimental, enquanto nos animais sob suplementação $5(\mathrm{P}<0,01)$ e 3 vezes por semana $(\mathrm{P}=0,058)$, houve redução de 26 e $16 \%$, respectivamente, de um período para outro. O efeito de período, principalmente no dia 2, parece ter sido mais importante nos animais sob suplementação em menor frequência.

De modo geral, de março para maio, houve redução de 5,21 e 16\% na concentração total de AGCC no rúmen de bovinos em pastagem de capim-marandu sob suplementação diária, 5 e 3 vezes por semana, respectivamente. A menor concentração dos AGCC no mês de maio é consequência da menor ingestão de forragem (Tabela 4) em relação ao mês de março.

As concentrações dos AGCC variaram entre os horários de coleta $(\mathrm{P}<0,05)$, com exceção do ácido butírico no dia 2, que se manteve ao longo do dia (Figura 2). No dia 1, as concentrações de AGCC, ácido acético e propiônico reduziram 3 horas após a suplementação e voltaram a aumentar 6 horas após a suplementação. O mesmo comportamento foi observado para o total de AGCC e o ácido propiônico no dia 2 . O ácido butírico no dia 1 atingiu concentração máxima 6 horas após o fornecimento do suplemento e não foi alterado no dia 2.

Tabela 5 - Concentração ruminal $(\mu \mathrm{mol} / \mathrm{dL})$ dos ácidos acético, propiônico e butírico e de ácidos graxos de cadeia curta totais (AGCC totais) e relação acético:propiônico (A:P) no rúmen de novilhos mantidos em pastagem de capim-marandu com três frequências de suplementação

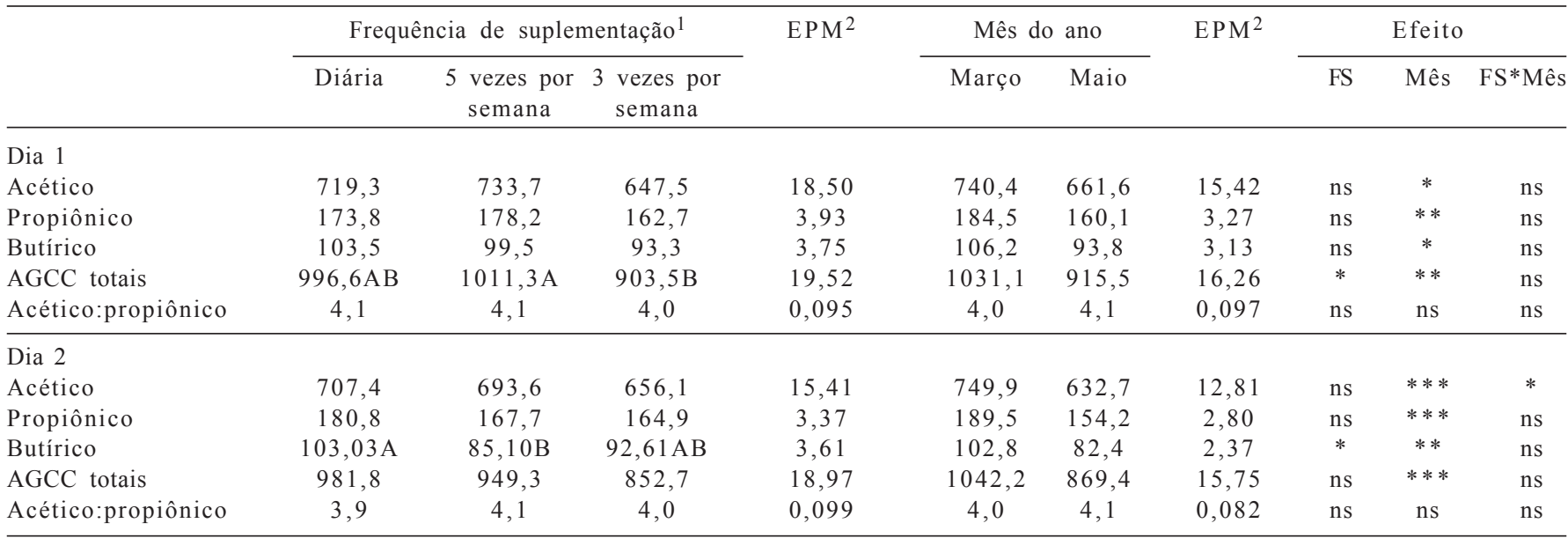

${ }^{1}$ Dia 1 = dia em que todos os grupos receberam suplemento; Dia 2 = dia em que somente o grupo sob suplementação diária recebeu

${ }^{2}$ Erro-padrão da média.

A,B Médias nas linhas com diferentes letras diferem significativamente para efeito de frequência de suplementação (FS); ns $\mathrm{P}>0,05 ; * \mathrm{P}<0,05 ; * * \mathrm{P}<0,01 ; * * * \mathrm{P}<0,001$. 

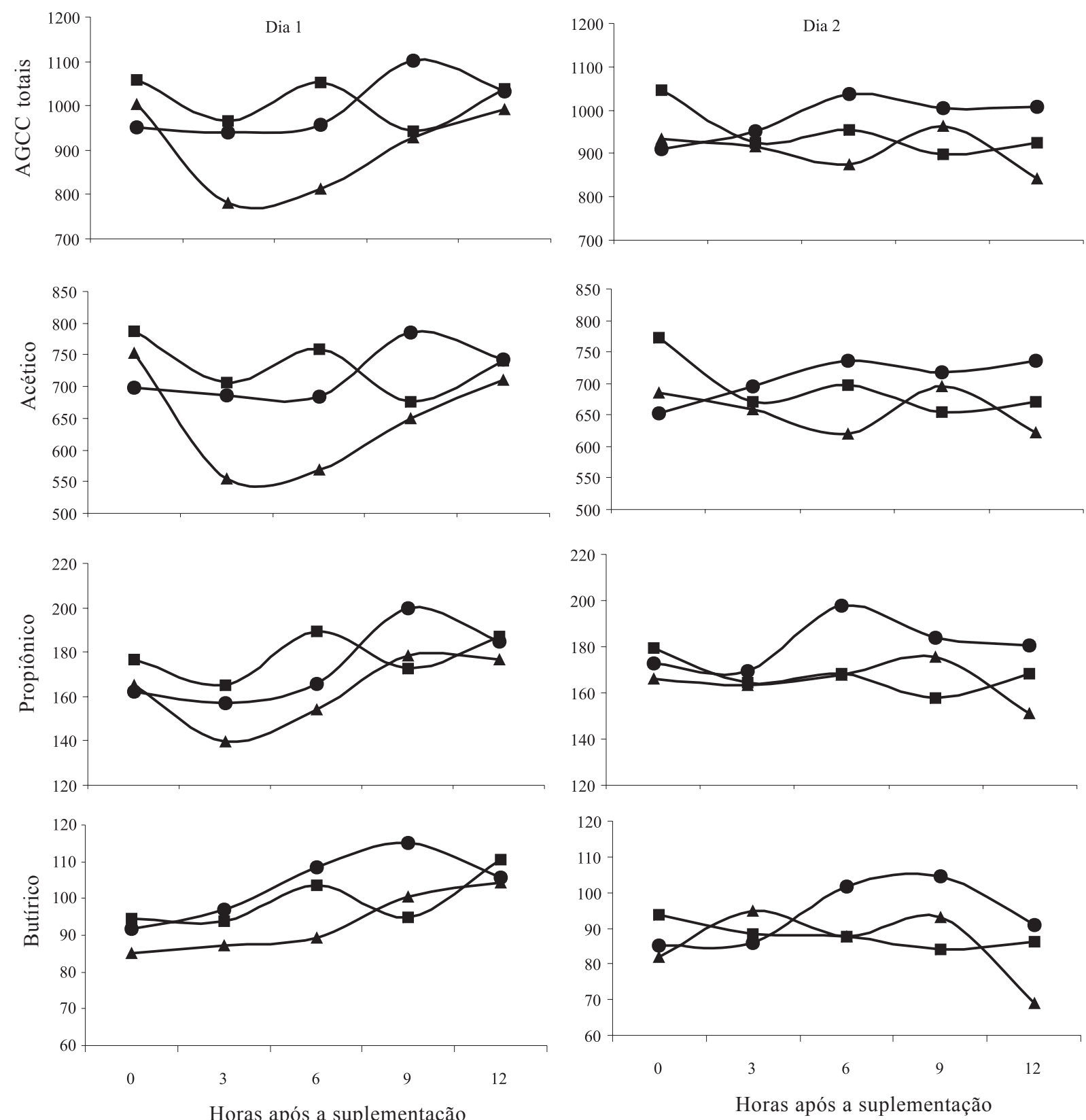

Dia 1 = dia em que todos os grupos receberam suplemento; Dia $2=$ dia em que somente o grupo TOD recebeu suplemento. Efeito de hora de coleta $(\mathrm{P}<0,05)$ para todas as variáveis no Dia 1; no Dia 2, efeito de hora para AGCC e ácidos propiônico $(\mathrm{P}<0,05)$; acético $=\mathrm{FS} \times$ hora $(\mathrm{P}<0,05)$; e butírico $(\mathrm{P}>0,05)$.

Figura 2 - Concentração ruminal ( $\mu \mathrm{mol} / \mathrm{dL})$ de ácidos graxos de cadeia curta (AGCC) totais e ácidos acético, propiônico e butírico no rúmen de novilhos mantidos em pastagem de capim-marandu sob suplementação diária $(\bullet), 5$ vezes por semana (ם) ou 3 vezes por semana $(\boldsymbol{\Delta})$.

\section{Conclusões}

A redução na frequência da suplementação de sete para cinco ou três vezes por semana não afeta a ingestão de matéria seca, tanto de forragem como total, nem a digestibilidade da matéria seca. Da mesma forma, o pH ruminal, as concentrações da amônia ruminal e dos ácidos graxos de cadeia curta, importantes para a manutenção adequada da fermentação ruminal, são mantidos quando a frequência de suplementação diminui. Do mês de março para o mês de maio, observou-se redução significativa na ingestão de forragem, na digestibilidade da matéria seca e nas concentrações dos ácidos graxos de cadeia curta, mas não houve alterações na concentração da amônia ruminal e no pH ruminal. 


\section{Agradecimentos}

À Fundação de Amparo à Pesquisa do Estado de São Paulo (FAPESP), pela concessão da bolsa de Doutorado à primeira autora. À Bellman Nutrição Animal, pela doação dos ingredientes do suplemento.

\section{Literatura Citada}

BEATY, J.L.; COCHRAN, R.C.; LINTZENICH, B.A. et al. Effect of frequency of supplementation and protein concentration in supplements on performance and digestion characteristics of beef cattle consuming low-quality forages. Journal of Animal Science, v.72, n.9, p.2475-2486, 1994.

BERCHIELLI, T.T.; CANESIN, R.C.; ANDRADE, P. Estratégias de suplementação para ruminantes em pastagem. Revista Brasileira de Zootecnia, v.35, p.353-370, 2006 (supl. especial).

BOHNERT, D.W.; SCHAUER, C.S.; BAUER, M.L. et al. Influence of rumen protein degradability and supplementation frequency on steers consuming low-quality forage: I. Site of digestion and microbial efficiency. Journal of Animal Science, v.80, n.6, p. 2967-2977, 2002a.

BOHNERT, D.W.; SCHAUER, C.S.; FALCK, S.J. et al. Influence of rumen protein degradability and supplementation frequency on steers consuming low-quality forage: II. Ruminal fermentation characteristics. Journal of Animal Science, v.80, n.11, p.2978-2988, 2002b.

BOHNERT, D.W.; SHAUER, C.S.; DelCURTO, T. Influence of rumen protein degradability and supplementation frequency on steers consuming low-quality forage: cow performance and efficiency of nitrogen use in wethers. Journal of Animal Science, v.80, n.6, p.1629-1637, 2002c.

CAREY, D.A.; CATON, J.S.; BIONDINI, M. Influence of energy source on forage fermentation in beef steers fed medium-quality Brome hay. Journal of Animal Science, v.71, n.8, p.2260-2269, 1993.

COLEMAN, S.W.; WYATT, R.D. Cottonseed meal or small grains forages as protein supplements fed at different intervals. Journal of Animal Science, v.55, n.1, p.11-17, 1982.

DETMANN, E.; VALADARES FILHO, S.C.; PINA, D.S. et al. Prediction of the energy value of cattle diets based on the chemical composition of the feeds under tropical conditions. Animal Feed Science and Technology, v.143, n.1-4, p.127-147, 2008.

DOVE, H.; MOORE, A.D. Using a least-square optimization procedure to estimate diet composition based on the alkanes of plant cuticular wax. Australian Journal of Agricultural Research, v.46, n.8, p.1535-1544, 1995.

DOVE, H.; WOOD, J.T.; SIMPSON, R.J. et al. Spray-topping annual grass pasture with glyphosate to delay loss of feeding value during summer. III. Quantitative basis of the alkane based procedures for estimating diet selection and herbage intake by grazing sheep. Australian Journal of Agricultural Research, v. 50, n.4, p.475-485, 1999.

FARMER, C.G.; COCHRAN, R.C.; NAGARAJA, T.G. et al. Ruminal and host adaptations to changes in frequency of protein supplementation. Journal of Animal Science, v.82, n.3, p.884-894, 2004.

FARMER, C.G.; COCHRAN, R.C.; SIMMS, D.D. et al. The effects of several supplementation frequencies on forage use and performance of beef cattle consuming dormant tallgrass prairie forage. Journal of Animal Science, v.79, n.6, p.2276-2285, 2001.

HUNT, C.W.; PARKINSON, J.F.; ROEDER, R.A. et al. The delivery of cottonseed meal at three different time intervals to steers fed low-quality grass hay: effects on digestion and performance. Journal of Animal Science, v.67, n.5, p.1360-1366, 1989.
HUNTER, R.A.; SIEBERT, B.D. Utilization of low-quality roughage by Bos Taurus and Bos indicus cattle. I. Rumen digestion. British Journal of Nutrition, v.53, p.637-648, 1985.

HUSTON, J.E.; ENGDAHL, B.S.; BALES, K.W. Supplemental feeding interval for adult ewes. Sheep Goat Research Journal, v. 15, p.87-93, 1999a.

HUSTON, J.E.; LIPPKE, H.; FORBES, T.D.A. Effects of supplemental feeding interval on adult cows in western Texas. Journal of Animal Science, v.77, p.3057-3067, 1999b.

JOHNSON, K.A.; JOHNSON, D.E. Methane emissions from Cattle. Journal of Animal Science, v.73, n.8, p.2483-2492, 1995.

LENG, R.A. Factors affecting the utilization of "poor-quality" forages by ruminants particularly under tropical conditions. Nutrition Research and Review, v.3, n.3, p.277-303, 1990.

LEVENTINI, M.W.; HUNT, C.H.; ROFFLER, R.E. et al. Effect of dietary level of barley-based supplements and ruminal buffer on digestion and growth by beef cattle. Journal of Animal Science, v.68, n.12, p.4334-4344, 1990.

MAYES, R.W.; LAMB, C.S.; COLGROVE, P.M. The use of dosed and herbage n-alkanes as markers for the determination of herbage intake. Journal of Agricultural Science, v.107, p.161-170, 1986 .

MILLER, T.L. Ecology of methane production and hydrogen sink in the rumen. In: ENGELHARDT, W.V.; LEONHARD-MAREK, S.; BREVES, G. et al. (Eds.). Ruminant physiology: digestion, metabolism, growth and reproduction. Stuttgart: Ferdinand Enke Verlag, 1995, p.317-332.

MORAIS, J.A.S. Estimativa da ingestão e digestibilidade em bovinos de corte alimentados com Brachiaria brizantha cv. Marandu. 2008. 119f. Tese (Doutorado em Zootecnia) Faculdade de Ciências Agrárias e Veterinárias, Jaboticabal, 2008.

MOULD, F.L.; ØRSKOV, E.R.; MANNS, O. Associative effects of mixed feeds. I. Effects of type and level of supplementation and the influence of the rumen $\mathrm{pH}$ on cellulolysis in vivo and dry matter digestion of various roughages. Animal Feed Science and Technology, v.10, p.15-30, 1983

OLIVÁN, M.; OSORO, K. Effect of temperature on alkane extraction from faeces and herbage. Journal of Agricultural Science, v.132, n.3, p.305-312, 1999

OWENS F.N.; ZINN, R. Metabolismo de la proteina em los rumiantes, In: $\mathrm{CHURCH}$, C.D. (Ed.). El rumiante: fisiologia digestiva y nutrición. Zaragoza: Acribia, 1988. p.255-282.

REIS, R.A.; DA SILVA, S.C. Consumo de forragem. In: BERCHIELLI, T.T.; PIRES, A.V.; OliveirA, S.G. (Eds.) Nutrição de ruminantes. Jaboticabal: FUNEP, 2006, p.79-103.

RUSSELL, J.B.; O'CONNOR, J.D.; FOX, D.G. et al. A net carbohydrate and protein system for evaluating cattle diets: I. Ruminal fermentation. Journal of Animal Science, v.70, n.11, p.3551-3561, 1992 .

SATTER, S.D.; SLYTER, L.L. Effects of ammonia concentration on rumen microbial protein production "in vitro". British Journal of Nutrition, v.32, p.245-249, 1974.

SCHAUER, C.S.; BOHNERT, D.W.; GANSKOPP. D.C. et al. Influence of protein supplementation frequency on cows consuming low-quality forage: performance, grazing behaviour, and variation in supplement intake. Journal of Animal Science, v.83, n.7, p.1715-1725, 2005.

SCHAUER, C.S.; CATON, J.; DROlC, D. et al. [2006]. Protein supplementation: daily, once every 5 days, or once every 10 days. 2006. Disponível em: <http://www.ag.ndsu.nodak.edu/hettinge/ livestock $/ 2006$ sheepbeefday $/ 5 \% 20-\% 20$ Sheep $\% 20$ Beef $\% 202006 \%$ 20Supp $\% 20$ Freq.pdf>. Acesso em: 15/8/2007.

SteEl, R.G.; TORRIE, J.H.; DICKEY, D.A. Principles and procedures of statistics. A biometrical approach. New York: McGraw-Hill Co, 1997. 666p.

YANG, C.J.; RUSSELL, J.B. The effect of monensin supplementation on ruminal ammonia accumulation in vivo and the numbers of amino acid-fermenting bacteria. Journal of Animal Science, v.71, n.12, p.3470-3476, 1993. 